dilutional effect of the bronchial wash procedure and extrapolating to allow comparison with sputum data in our laboratory for CF and $\mathrm{BE}$, the relative load of bacteria from the genera Streptococcus, Prevotella and Veillonella is similar in these three airway diseases. The potential role of these bacteria in the progression and pathogenesis of COPD requires further investigation.

\section{S105 LONGITUDINAL MICROBIOLOGY OF ADULT NON-CF BRONCHIECTASIS}

doi:10.1136/thoraxjnl-2011-201054b.105

${ }^{1}$ W A Haja Sahabudeen, ${ }^{2} \mathrm{D}$ L Smith. ${ }^{1}$ University of Bristol, Bristol, UK; ${ }^{2}$ North Bristol Lung Centre, Bristol, UK

Introduction and Objectives A longitudinal microbiologic profile in adults with non-CF bronchiectasis (nCF-Br) is helpful in directing appropriate antibiotic therapy and may also have implications for prognosis. Information in this area is scarce with limited published data and small sample sizes of available studies. We have looked at longitudinal records from a group of nCF- $\mathrm{Br}$ patients attending a specialist clinic.

Methods All available sputum microbiology results for patients over a 5-year period were analysed.

Results 158 patients, average age 64.5 years (range 18-87 years), $58 \mathrm{M}: 100 \mathrm{~F}$, had 2 or more samples available for analysis. The majority (149 (94.3\%)) of these had a HRCT diagnosis. 23 (14.6\%) of the 158 patients cultured no organisms. Abstract S105 table 1 shows the distribution of organisms found colonising the remaining 141 patients. In a subset of 72 patients with $=6$ samples taken over an average period of 2.7 (SD 1.0) years, $2(2.8 \%)$ grew no organisms, 17 (23.6\%) grew a single organism, 21 (29.2\%) grew two, 14 (19.4\%) grew three, $18(25 \%)$ grew four or more different organisms on different occasions. Of the 806 samples analysed in this subset of patients, the majority grew single organisms, $83(10.3 \%)$ reported 2 or more isolates. Among 46 of these 72 in whom Pseudomonas spp. was isolated, the initial isolate was followed by persistent colonisation in 30 (65.2\%).

Conclusions The distribution of colonising pathogens among our larger patient group is similar to those found in other studies. We have shown a higher degree of variation in organisms found over time than has been previously shown. ${ }^{1}$

Abstract S105 Table 1 Distribution of organism colonisation in patients with non-CF bronchiectasis

\begin{tabular}{lc}
\hline Organism & $\begin{array}{l}\text { Colonisation rate } \\
\text { n (\%) }\end{array}$ \\
\hline Pseudomonas aeruginosa & $42(26.6)$ \\
Haemophilus influenzae & $22(13.9)$ \\
Coliforms (including Klebsiella spp., Serratia & $14(8.9)$ \\
spp., Proteus spp., Escherichia coli and & \\
Enterobacter clocae) & \\
Streptococcus pneumoniae & $11(7.0)$ \\
Aspergillus spp. & $8(5.1)$ \\
Moraxella catarrhalis & $6(3.8)$ \\
Staphylococcus aureus & $3(1.9)$ \\
MRSA & $2(1.3)$ \\
Others & $2(1.3)$ \\
No pathogens isolated & $23(14.6)$ \\
\hline
\end{tabular}

\section{REFERENCE}

1. Nicotra MB, Rivera M, Dale AM, et al. Clinical, pathophysiologic, and microbiologic characterisation of bronchiectasis in an ageing cohort. Chest 1995; 108:955-61.

\section{S106 A RANDOMISED DOUBLE BLIND 13 WEEK CROSSOVER TRIAL OF HYPERTONIC SALINE (HTS) (6\%) VS ISOTONIC SALINE (ITS) (0.9\%) IN PATIENTS WITH BRONCHIECTASIS}

doi:10.1136/thoraxjnl-2011-201054b.106

${ }^{1} \mathrm{~J} M$ Bradley, ${ }^{2} \mathrm{~K}$ Treacy, ${ }^{1} \mathrm{~B}$ O'Neill, ${ }^{1} \mathrm{~F}$ McCourt, ${ }^{3} \mathrm{~L}$ Green, ${ }^{1} \mathrm{E}$ Gardner, ${ }^{2} \mathrm{~J}$ S Elborn. ${ }^{1}$ University of Ulster, Newtownabbey, Northern Ireland; ${ }^{2}$ Queen's University, Belfast, Northern Ireland; ${ }^{3}$ Belfast HSC Trust, Belfast, Northern Ireland

Background Hypertonic saline is a hyperosmolar agent which increases mucociliary clearance in CF but there is little data available on its effectiveness in bronchiectasis.

Aim To determine the effectiveness of nebulised HTS (6\%) in comparison to ITS $(0.9 \%)$ on $24 \mathrm{~h}$ sputum production, lung function and patient related outcome measures in patients with stable bronchiectasis.

Design Proof of concept double blind cross-over study.

Methods Patients with clinical and CT diagnosis of bronchiectasis were randomised (double-blinded) to receive two consecutive 4week treatments of twice daily nebulised HTS (6\%) or ITS $(0.9 \%)$ each masked with quinine sulphate; with a 2 -week washout period between treatment cycles. The order of treatment was determined using concealed computerised randomised allocation performed by a statistician not involved in study conduct (EG).

Outcomes $24 \mathrm{~h}$ sputum volume/weight, lung function $\left(\mathrm{FEV}_{1}\right)$, cough (Leicester Cough Questionnaire, LCQ) and quality of life (Quality of Life Questionnaire-Bronchiectasis, QOL-B), and adverse events.

Results 19 patients (9M: 10F; Mean (SD): 61 (11) yrs; FEV 1,57 (23) $\%$ predicted; daily sputum weight 17 (17) grams) were recruited into this study. 13 patients completed both arms of the study. A patient and co-ordinator questionnaire indicated that the study design and the use of quinine sulphate was successful in achieving double blinding and masking HTS/ITS. HTS had a small to large effect (effect sizes $0.01-0.14$ ) on sputum and $\mathrm{FEV}_{1}, \mathrm{LCQ}$, and QOL-B. The overall trend was a benefit from HTS compared to ITS. There was a significant improvement in the physical domain of the LCQ $(-0.8$ (0.9), $\mathrm{p}=0.01)$ and the respiratory symptoms domain of the QOL-B $(-11.6(17.7), p=0.03)$ in the HTS cycle compared to the ITS. There was no differences in adverse events between the cycles.

Conclusion This study suggests that HTS may be effective in bronchiectasis. It provides data on study feasibility (study design and sample size) to justify a Phase 3 multicentre clinical trial to investigate the effectiveness of HTS in bronchiectasis.

\section{S107 THE INFLUENCE OF VIRAL SYMPTOMS IN INFECTIVE EXACERBATIONS OF NON-CYSTIC FIBROSIS BRONCHIECTASIS}

doi:10.1136/thoraxjnl-2011-201054b.107

${ }^{1} \mathrm{M}$ P Smith, ${ }^{2} \mathrm{C}$ J Doherty, ${ }^{2} \mathrm{~J}$ R W Govan, ${ }^{1} \mathrm{~K}$ Templeton, ${ }^{1} \mathrm{~A}$ T Hill. ${ }^{1}$ Royal Infirmary of Edinburgh, Edinburgh, UK; ${ }^{2}$ University of Edinburgh, Edinburgh, UK

Aim The aim of this study was to determine whether presence of viral symptoms influenced severity or outcome of exacerbations of bronchiectasis.

Methods Patients presenting to our outpatient service with exacerbations of bronchiectasis (defined as increasing cough, increasing sputum volume and worsening sputum purulence) requiring 2 weeks' oral antibiotic therapy were included. Patients reporting viral symptoms (defined as fever and any two of: unusual tiredness, headache, rhinorrhoea, sore throat, anorexia, myalgia, diarrhoea or vomiting) were compared with those who did not. The following outcomes were used to assess the exacerbation and response to 2 weeks' antibiotic therapy between the two groups: sputum 
Abstract S107 Table 1

\begin{tabular}{|c|c|c|c|c|c|c|}
\hline Variable & $\begin{array}{l}\text { Exacerbation Start } \\
\text { (No viral symptoms) } n=23\end{array}$ & $\begin{array}{l}\text { End Exacerbation } \\
\text { (No viral symptoms) } n=23\end{array}$ & p Value & $\begin{array}{l}\text { Start Exacerbation } \\
\text { (Viral symptoms) } n=17\end{array}$ & $\begin{array}{l}\text { End Exacerbation } \\
\text { (Viral symptoms) } n=17\end{array}$ & p Value \\
\hline $24 \mathrm{~h}$ sputum volume (ml) & $15(10-15)$ & $3(0-10)$ & $<0.0001$ & $20(10-20)$ & $5(2-8)$ & $<0.0001$ \\
\hline$\%(n)$ purulent sputum & $95.6(22)$ & $26.1(6)$ & $<0.0001$ & $82.3(14)$ & $0(0)$ & $<0.0001$ \\
\hline ISWT (m) & $210(80-350)$ & $350(140-430)$ & $<0.0001$ & $300(100-410)$ & $380(255-585)$ & $<0.0001$ \\
\hline ESR $(\mathrm{mm} / \mathrm{hr})$ & $26(14-44)$ & $18(9-41)$ & 0.04 & $14(8.5-25)$ & $12(7.5-14)$ & 0.01 \\
\hline $\operatorname{CRP}(\mathrm{mg} / \mathrm{l})$ & $14(10-33)$ & $5(2-15)$ & $<0.0001$ & $14(8-26.5)$ & $5(2-8)$ & 0.002 \\
\hline WCC $\left(\times 10^{9}\right)$ (range $\left.4-11\right)$ & $9.3(7.3-12)$ & $8.6(7.2-9.7)$ & 0.005 & $8(6-12.2)$ & $7.1(5.4-8.75)$ & 0.04 \\
\hline $\begin{array}{l}\text { Neutrophil count }\left(\times 10^{9}\right) \\
\text { (range } 2-7.5)\end{array}$ & $6.42(5.5-8.41)$ & $5.22(4.64-6.76)$ & 0.02 & $5.44(3.5-8.86)$ & $3.85(3.06-6.2)$ & 0.07 \\
\hline $\begin{array}{l}\text { Lymphocyte count }\left(\times 10^{9}\right) \\
\text { (range } 1.5-4)\end{array}$ & $1.76(1.08-2.18)$ & $1.71(1.32-2.13)$ & 0.55 & $1.82(1.41-2.63)$ & $1.76(1.52-2.16)$ & 0.8 \\
\hline $\begin{array}{l}\text { Pathogens isolated } \\
\text { from sputum } \% \text { (n) }\end{array}$ & $100(23)$ & $30.4(7)$ & 0.009 & $100(17)$ & $23.5(4)$ & $<0.0001$ \\
\hline
\end{tabular}

CRP, C reactive protein; ESR, Erythrocyte Sedimentation Rate; WCC, White cell count

bacteriology; sputum colour; 24 h sputum volume; respiratory viral PCR [Influenza A and B; Respiratory Syncytial Virus; Parainfluenza Type 1, 2, 3; Adenovirus]; incremental shuttle walk test; total white cell count; lymphocyte count; neutrophil count; $C$ reactive protein; Erythrocyte Sedimentation Rate. Data is presented as median (IOR) and groups compared using the Mann-Whitney U Test.

Results 40 patients were included. 17 reported viral symptoms. Of the 17 patients who reported viral symptoms, only 2 had positive viral PCR [Influenza Type B $(n=1)$ and Respiratory Syncytial Virus $(n=1)]$. No patient in the group not reporting viral symptoms had a positive viral PCR. At the start of the exacerbation, there was no significant difference in any parameter between the groups and both groups had a similar and positive impact with 2-week course of antibiotic therapy. Abstract S107 table 1 details the measurements at the start and end of the exacerbation for each group.

Conclusion There was a low prevalence of positive virology despite the presence of viral symptoms and outcomes were similar in patients with and without viral symptoms. Larger cohort studies are needed.

\section{S108 EXPERT CONSENSUS ON DIAGNOSTIC CRITERIA AND TERTIARY SERVICE REQUIREMENTS FOR BRONCHIECTASIS}

doi:10.1136/thoraxjnl-2011-201054b.108

${ }^{1} \mathrm{~J}$ Holme, ${ }^{2} \mathrm{~S}$ Bianchi, ${ }^{3} \mathrm{I}$ Clifton, ${ }^{4} \mathrm{~A}$ De-Soyza, ${ }^{2} \mathrm{~F}$ Edenborough, ${ }^{3} \mathrm{D}$ Peckham, ${ }^{2} \mathrm{O}$ Pirzada, ${ }^{5} \mathrm{P}$ Walker, ${ }^{6} \mathrm{M}$ Walshaw, ${ }^{1} \mathrm{R}$ Niven. ${ }^{1}$ University Hospital of South Manchester NHS Foundation Trust, Manchester, UK; ${ }^{2}$ Sheffield Teaching Hospitals NHS Foundation Trust, Sheffield, UK; ${ }^{3}$ Leeds Teaching Hospitals NHS Trust, Leeds, UK; ${ }^{4}$ Newcastle Hospitals NHS Foundation Trust, Newcastle, UK; ${ }^{5}$ Aintree University Hospitals NHS Foundation Trust, Liverpool, UK; ${ }^{6}$ Liverpool Heart and Chest Hospital NHS Foundation Trust, Liverpool, UK

Introduction There are no agreed diagnostic criteria for bronchiectasis and no stated minimum requirements for a tertiary service. The Northern Bronchiectasis Group aimed to use the validated RAND technique to form consensus opinions on these issues. Method Following literature review, a questionnaire was devised containing 89 statements relevant to the topics above. Eight expert members rated their level of agreement with the statements from 1 (not relevant) to 9 (mandatory). Following a group debate about these statements, the experts re-structured some statements then re-rated the questionnaire. Consensus agreement, indifference or disagreement was reached if $7 / 8$ members' scores were in the 7-9, 4-6 or 1-3 ranges respectively.

Results There was consensus agreement for 31/89, consensus indifference for $5 / 89$ and consensus disagreement for $12 / 89$ state- ments. Consensus was not reached for 41/89 statements. It was agreed daily sputum production would prompt investigation for bronchiectasis, CT was always necessary, and the following factors, support the diagnosis: bronchoarterial ratio $>1.0$, non-tapering bronchi, thickened airway walls, irreversible changes. It was agreed that a tertiary service should provide: access to HRCT, spirometry, routine and fungal sputum cultures, ciliary function testing; functional antibodies and immunoglobulins for all, antibiotic \& hypertonic saline nebuliser challenges, nebuliser loan and maintenance, home iv antibiotic service (preferably by patients in their own homes), portacath insertion, physiotherapy at least annually, access to a dietician, immunologist, microbiologist with an interest in bronchiectasis and pulmonary rehabilitation. Specialist nurses could see selected patients and separate clinics are desirable for patients colonised with pseudomonas. There was indifference to the availability of telephone consultations, posted sputum analysis, iv antibiotic service based in the community (not in patients' home), a patient support group and patient educational sessions. Consensus was not reached regarding if respiratory infection, bronchoarterial ratios of $>1.5$ or $>2.0$ or abnormal spirometry are necessary to diagnose bronchiectasis; or if a consultant should see patients at most visits, iv antibiotics could be given by a nurse in the patients home and if access to palliative care was necessary in a tertiary service.

Conclusion Comprehensive consensus statements regarding the diagnostic criteria for bronchiectasis and tertiary service requirements have been formed.

\section{ILD mechanisms}

\section{S109 CONTRIBUTION OF ABERRANT MONOCYTE-NATURAL KILLER T (NKT) CELL AXIS TO IMMUNE-PATHOLOGY IN SARCOIDOSIS}

doi:10.1136/thoraxjnl-2011-201054b.109

A P Crawshaw, W L Kok, L Denney, L-P Ho. Human Immunology Unit, Weatherall Institute of Molecular Medicine, University of Oxford, Oxford, UK

Introduction Sarcoidosis is a multisystem disorder characterisedby an overactive CD4 (T-helper 1) cell response to an undefined antigen, macrophage activation and granuloma formation. It has also been shown that monocytes (precursors to macrophages) are increased in sarcoidosis. We have shown that NKT cells, a specialised subset of immuneregulatory $\mathrm{T}$ cells, are deficient in sarcoidosis, and that in NKT knock-out mice, monocytes accumulate at sites of inflammation in both models of influenza A infection and multiple sclerosis. Here, we hypothesise that NKT cells control monocyte function and 